\title{
Comparison of the ventilation characteristics in two adult oscillators: a lung model study
}

Tetsuya Yumoto ${ }^{1}$, Takahisa Fujita², Sunao Asaba², Shunsuke Kanazawa², Atsunori Nishimatsu², Hideo Yamanouchi ${ }^{3}$, Satoshi Nakagawa ${ }^{4}$ and Osamu Nagano ${ }^{3^{*}}$ (i)

* Correspondence: onagano2004@ yahoo.co.jp

${ }^{3}$ Department of Disaster and Emergency Medicine, Kochi University Medical School, 185-1, Kohasu, Oko-cho, Nankoku, Kochi 783-8505, Japan

Full list of author information is available at the end of the article

\section{Springer Open}

\begin{abstract}
Background: Two recent large randomized controlled trials did not show the superiority of high-frequency oscillatory ventilation (HFOV) in adults with ARDS. These two trials had differing results, and possible causes could be the different oscillators used and their different settings, including inspiratory time \% (IT\%). The aims of this study were to obtain basic data about the ventilation characteristics in two adult oscillators and to elucidate the effect of the oscillator and IT\% on ventilation efficiency.

Methods: The Metran R100 or SensorMedics 3100B was connected to an original lung model internally equipped with a simulated bronchial tree. The actual stroke volume (aSV) was measured with a flow sensor placed at the Y-piece. Carbon dioxide $\left(\mathrm{CO}_{2}\right)$ was continuously insufflated into the lung model $\left(\dot{\mathrm{V}} \mathrm{CO}_{2}\right)$, and the partial pressure of $\mathrm{CO}_{2}$ $\left(\mathrm{PCO}_{2}\right)$ in the lung model was monitored. Alveolar ventilation ( $\left.\dot{V} \mathrm{~A} ; \mathrm{L} / \mathrm{min}\right)$ was estimated as $\dot{\mathrm{V}} \mathrm{CO}_{2}$ divided by the stabilized value of $\mathrm{PCO}_{2}$. $\dot{V} \mathrm{~A}$ was evaluated with several stroke volume settings in the R100 (IT =50\%) or several airway pressure amplitude settings in the $3100 \mathrm{~B}(\mathrm{IT}=33 \%, 50 \%)$ at a frequency of 6 and $8 \mathrm{~Hz}$, a mean airway pressure of 25 $\mathrm{cmH}_{2} \mathrm{O}$, and a bias flow of $30 \mathrm{~L} / \mathrm{min}$. Assuming that $\dot{\mathrm{V}} \mathrm{A}=$ frequency $^{a} \times \mathrm{aSV}^{b}$, values of $a$ and $b$ were determined. Ventilation efficiency was calculated as $\dot{V} A$ divided by actual minute ventilation.
\end{abstract}

Results: The relationship between aSV and $\dot{V} A$ or ventilation efficiency were different depending on the oscillator and IT\%. The values of $a$ and $b$ were $0<a<1$ and $1<b<2$ and were different for three conditions at both frequencies. $\dot{V} A$ and ventilation efficiency were highest with R100 (IT=50\%) and lowest with 3100B (IT = 33\%) for high aSV ranges at both frequencies.

Conclusions: In this lung model study, ventilation characteristics were different depending on the oscillator and IT\%. Ventilation efficiency was highest with R100 $(I T=50 \%)$ and lowest with 3100B (IT = 33\%) for high aSV ranges.

Keywords: High-frequency oscillatory ventilation (HFOV), Adult oscillator, Inspiratory time \% (IT\%), Ventilation efficiency, Actual stroke volume

\section{Background}

Two recent large randomized controlled trials did not show the superiority of high-frequency oscillatory ventilation (HFOV) in adults with ARDS $[1,2]$. These two trials had differing results, and possible causes could be the different oscillators used

(c) The Author(s). 2019 Open Access This article is distributed under the terms of the Creative Commons Attribution 4.0 International License (http://creativecommons.org/licenses/by/4.0/), which permits unrestricted use, distribution, and reproduction in any medium, provided you give appropriate credit to the original author(s) and the source, provide a link to the Creative Commons license, and indicate if changes were made. 
and their different settings, including mean airway pressure (MAP), frequency, and inspiratory time \% (IT\%). The difference in the MAP has been discussed and examined [3-6], and animal studies have shown that higher frequencies could improve the lung protective effect $[7,8]$. However, other issues have not been focused on.

Because adult oscillators have no function to monitor actual SV (aSV), the aSV in the two trials (OSCILLATE and OSCAR) were not clear $[1,2]$. However, some studies have reported that the aSV during HFOV could be higher than the anatomical dead space volume at low frequencies [8-10]. Recently, we have examined the effect of bias flow (BF) rate on ventilation efficiency using a lung model and reported that the ventilation efficiency improved with a BF of $30 \mathrm{~L} / \mathrm{min}$ or more compared to that with a BF of $20 \mathrm{~L} /$ min or less in the R100 oscillator (Metran Co. Ltd., Kawaguchi, Saitama, Japan) at $8 \mathrm{~Hz}$ [11]. If the BF rate is inadequate, the required aSV consequently increases in order to obtain the same alveolar ventilation (VA) for a given frequency. Therefore, ventilation efficiency is one factor to determine the amount of required aSV.

\section{Methods}

\section{Experimental setting}

The R100 or the SensorMedics 3100B (CareFusion, Yorba Linda, CA, USA) oscillator was connected to the lung model via an angle-type connector and an endotracheal tube (ETT) with an internal diameter of $8.0 \mathrm{~mm}$ and a length of $30 \mathrm{~cm}$ (Fig. 1). A microelectromechanical systems mass flow sensor (Siargo FS6022B150, Siargo Ltd., Santa Clara, CA, USA) was placed between the angle-type connector and the Y-piece for measuring aSV. The total dead space volume (VD) was approximately $110 \mathrm{~mL}$, and the measured airway resistance was approximately 2,5 , and $8 \mathrm{cmH}_{2} \mathrm{O} / \mathrm{L} / \mathrm{sec}$ with a flow of 10,60 , and $120 \mathrm{~L} / \mathrm{min}$, respectively. The common oscillator settings during the experiments

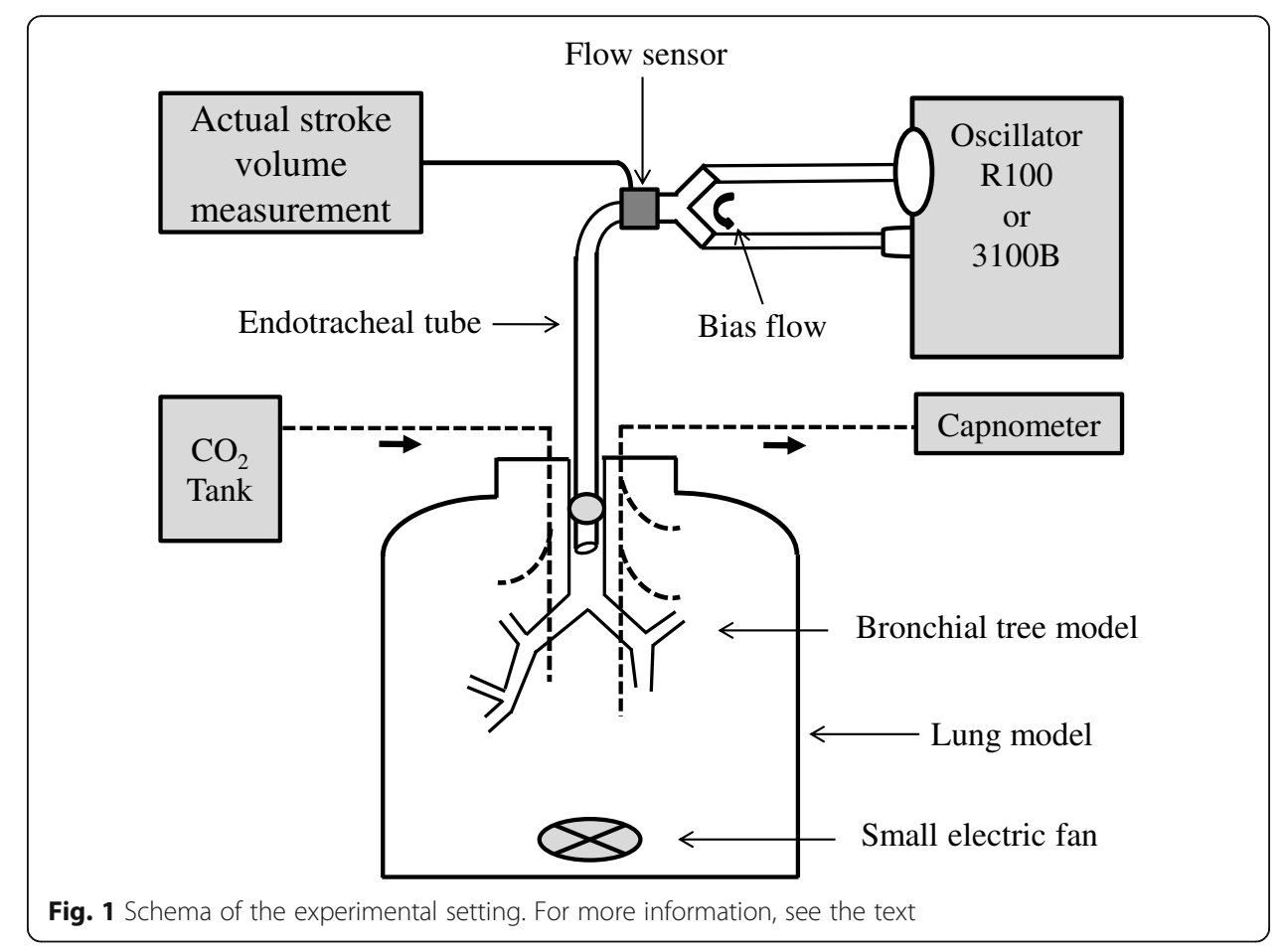


were as follows: MAP of $25 \mathrm{cmH}_{2} \mathrm{O}, \mathrm{BF}$ of $30 \mathrm{~L} / \mathrm{min}$, and fraction of inspired oxygen of 0.21 . The heated humidifier was turned off (hollow fiber type, R100) or removed from the circuit (chamber type, 3100B).

\section{Measurement of actual stroke volume}

aSV was measured with a prototype stroke volume (SV) measurement system (Metran Co. Ltd., Kawaguchi, Saitama, Japan). In this system, the analog flow signal was sampled at $200 \mathrm{~Hz}$ and digitally integrated to determine expiratory SV every $1 \mathrm{~s}$ using a computer data acquisition system (LabView Ver.14, National Instruments, Austin, TX, USA). The mean value of 60 data measurements for 1 min was calculated as the aSV.

\section{Lung model}

The lung model consisted of a 20-L airtight rigid plastic container internally equipped with a simulated bronchial tree model (KYOTO KAGAKU Co. Ltd., Kyoto, Japan) which had 3 to 7 steps of bifurcations to 20 segmental bronchial branches [11] (Fig. 1). The top of the ETT was located $3.5 \mathrm{~cm}$ from the carina. The total $20 \mathrm{~L}$ volume of the container accounts for an adiabatic static compliance of $19.3 \mathrm{~mL} / \mathrm{cmH}_{2} \mathrm{O}$ (approximately equal to the severe ARDS [12]) due to gas compression. The container had two ports for gas insufflation and for gas sampling. A small electrical fan was placed horizontally on the bottom to assist gas mixing and to assure homogeneous $\mathrm{CO}_{2}$ distribution in the container.

\section{Measurement of alveolar ventilation}

Carbon dioxide $\left(\mathrm{CO}_{2}\right)$ was insufflated into the lung model at approximately $200 \mathrm{~mL} / \mathrm{min}$ (float type area flowmeter), and continuous gas sampling was performed from the lung model using a capnometer (Life Scope TR, NIHON KOHDEN Co., Tokyo, Japan) (Fig. 1). The gas sampling rate of the capnometer was set at $200 \mathrm{~mL} / \mathrm{min}$. The partial pressure of $\mathrm{CO}_{2}\left(\mathrm{PCO}_{2} ; \mathrm{mmHg}\right)$ was monitored by the capnometer, and the stabilized value was recorded. The actual minute volume of insufflated $\mathrm{CO}_{2}\left(\dot{\mathrm{V} C O}{ }_{2} ; \mathrm{mL} / \mathrm{min}\right)$ was calculated by the measurement of $\mathrm{PCO}_{2}$ using the capnometer when it was mixed with oxygen at $5 \mathrm{~L} /$ min (fixed-type flowmeter). This was performed before starting the experiment and was confirmed every 1 to $2 \mathrm{~h}$. The $\dot{\mathrm{V}} \mathrm{A}$ was estimated by applying the alveolar ventilation equation $\left(\mathrm{PCO}_{2}=0.863 \times \dot{\mathrm{V} C O} \mathrm{C}_{2} / \dot{\mathrm{V}} \mathrm{A}, \mathrm{PCO}_{2}\right.$, and $\left.\dot{\mathrm{V}} \mathrm{A}: \mathrm{BTPS}, \dot{\mathrm{V} C O}{ }_{2} \mathrm{STPD}\right)$, though the equation was rearranged and used as $\dot{\mathrm{VA}}=\dot{\mathrm{V} C \mathrm{CO}_{2}} / \mathrm{PCO}_{2}$ because all experiments were done under room temperature and dry conditions.

Although the SV can be set at up to $285 \mathrm{~mL}$ at a frequency of $6 \mathrm{~Hz}$ and $205 \mathrm{~mL}$ at a frequency of $8 \mathrm{~Hz}$ in the R100 oscillator, the measurable range of the flow sensor was limited. Therefore, V A was evaluated with the SV setting (sSV) from 80 to $180 \mathrm{~mL}(10 \mathrm{~mL}$ increments). The IT\% was fixed at 50\% in the R100 oscillator. In the 3100B oscillator, the IT\% was set at $50 \%$ or $33 \%$, and $\dot{\mathrm{V}} \mathrm{A}$ was evaluated with several setting amplitudes (Amp; 5 $\mathrm{cmH}_{2} \mathrm{O}$ increments, up to the maximum) at a frequency of 6 and $8 \mathrm{~Hz}$. The minimum Amp setting was $20 \mathrm{cmH}_{2} \mathrm{O}(\mathrm{IT}=50 \%, 6 \mathrm{~Hz}), 30 \mathrm{cmH}_{2} \mathrm{O}(\mathrm{IT}=33 \%, 6 \mathrm{~Hz}$ and IT $=50 \%, 8$ $\mathrm{Hz})$, and $35 \mathrm{cmH}_{2} \mathrm{O}(\mathrm{IT}=33 \%, 8 \mathrm{~Hz})$. Assuming that $\dot{\mathrm{VA}}=$ frequency $^{a} \times \mathrm{aSV}^{b}$ [13], values of $a$ and $b$ were determined. The ratio of $\dot{\mathrm{V}} \mathrm{A}$ to the actual minute ventilation (a $\dot{\mathrm{V}} \mathrm{E}$; $\mathrm{aSV} / 1000 \times$ frequency $\times 60, \mathrm{~L} / \mathrm{min})$ was calculated $(\dot{\mathrm{VA}} / \mathrm{a} \dot{\mathrm{V}} \mathrm{E})$ as an index for ventilation efficiency. 
In both oscillators, VA was also evaluated with the targeted aSV of 80, 120, and 160 $\mathrm{mL}$ at $6 \mathrm{~Hz}$ and 80,100 , and $120 \mathrm{~mL}$ at $8 \mathrm{~Hz}$, and $\dot{\mathrm{V}} \mathrm{A} / \mathrm{a} \dot{\mathrm{VE}}$ was calculated (additional experiment). This additional experiment was for statistical analysis.

Each experiment was conducted five times.

\section{Statistical analysis}

The statistical analysis was performed by BellCurve for Excel ver. 2.02 (SSRI Co. Ltd., Tokyo, Japan) using one-way analysis of variance followed by Tukey's test. $P<0.05$ was considered statistically significant. Curve fitting was also performed using the same software.

\section{Results}

Figure 2 shows the relationships between aSV and sSV (Fig. 2a) and between Amp and sSV (Fig. 2b) in the R100 (IT =50\%). The aSV was linearly proportional to the sSV, and the Amp was correlated exponentially to the sSV at both frequencies. Figure 3 shows the relationships between Amp and aSV in the 3100B oscillator (Fig. 3a: IT $=50 \%$, Fig. $3 \mathrm{~b}$ : IT $=33 \%$ ). The maximum Amp with the IT of $50 \%$ was $78.4 \pm 1.4 \mathrm{cmH}_{2} \mathrm{O}$ at 6 $\mathrm{Hz}$ and $77.4 \pm 0.5 \mathrm{cmH}_{2} \mathrm{O}$ at $8 \mathrm{~Hz}$, and those with the IT of $33 \%$ were $84.2 \pm 1.8 \mathrm{cmH}_{2} \mathrm{O}$ at $6 \mathrm{~Hz}$ and $85.8 \pm 1.1 \mathrm{cmH}_{2} \mathrm{O}$ at $8 \mathrm{~Hz}$ (mean \pm standard deviation). The aSV was well correlated to the Amp at both frequencies. aSV is generally plateaued with an Amp of $70 \mathrm{cmH}_{2} \mathrm{O}$ or more at $6 \mathrm{~Hz}$ with the IT of $33 \%$ and with an Amp of $75 \mathrm{cmH}_{2} \mathrm{O}$ or more with other settings.

Figure 4 shows the relationships between aSV $(\mathrm{L})$ and $\dot{\mathrm{V}} \mathrm{A}(\mathrm{L} / \mathrm{min})$ at $6 \mathrm{~Hz}$ (Fig. $4 \mathrm{a})$ and $8 \mathrm{~Hz}$ (Fig. 4b). The indicated individual datasets in the $3100 \mathrm{~B}$ are those with the Amp up to $70 \mathrm{cmH}_{2} \mathrm{O}$ at $6 \mathrm{~Hz}$ with the IT of $33 \%$ and those with an Amp up to 75 $\mathrm{cmH}_{2} \mathrm{O}$ with other settings. $\dot{\mathrm{V}} \mathrm{A}$ was correlated exponentially to the aSV in three condi-

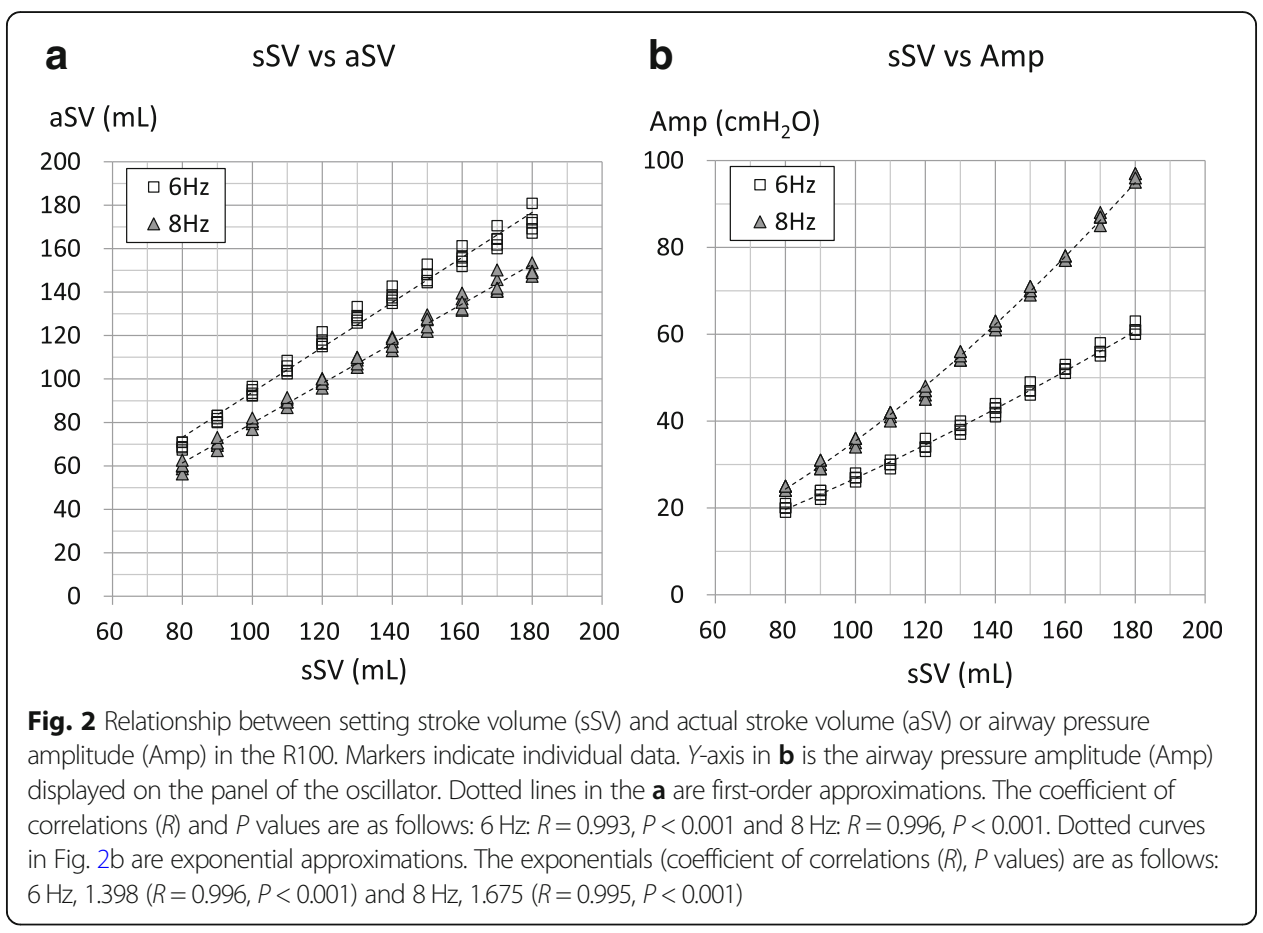



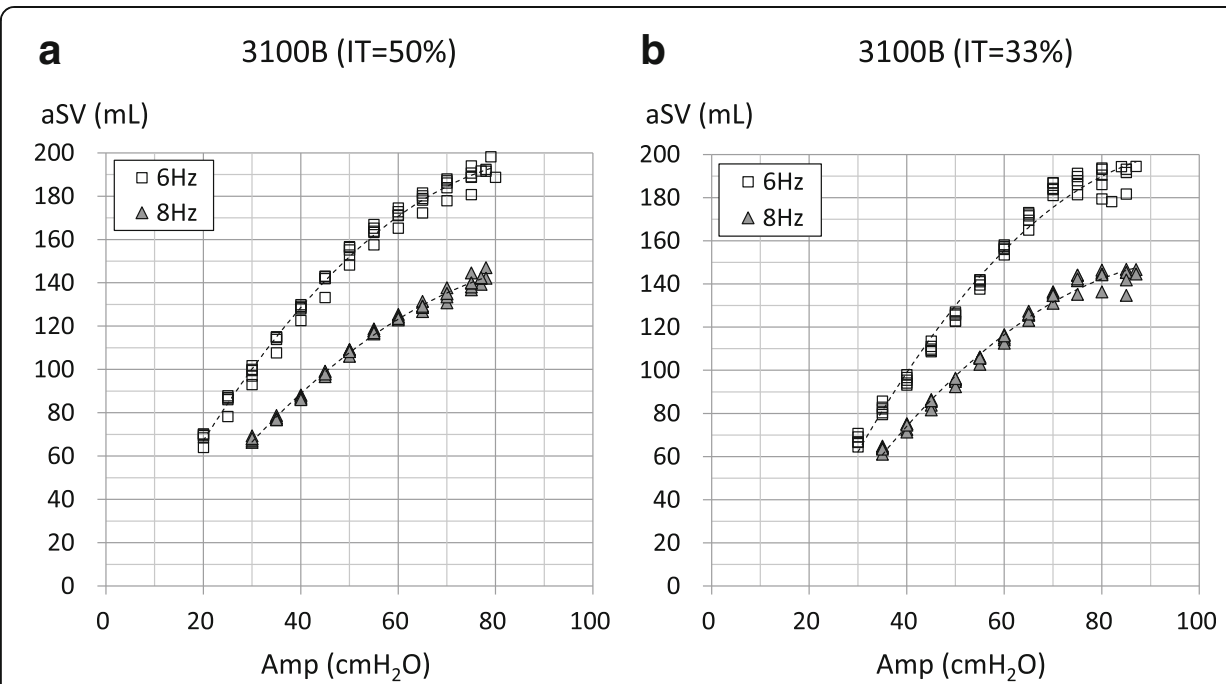

Fig. 3 Relationship between airway pressure amplitude (Amp) and actual stroke volume (aSV in the 3100B oscillator. Markers indicate individual data. X-axis is the airway pressure amplitude (Amp) displayed on the panel of the oscillator. a The results of $I T=50 \%$. $\mathbf{b}$ The results of $I T=33 \%$. The maximum Amp with the IT of $50 \%$ was $78.4 \pm 1.4 \mathrm{cmH}_{2} \mathrm{O}$ (mean $\pm \mathrm{SD}$ ) at $6 \mathrm{~Hz}$ and $77.4 \pm 0.5 \mathrm{cmH}_{2} \mathrm{O}$ at $8 \mathrm{~Hz}\left(\mathbf{a}\right.$ ), and those with the IT of $33 \%$ were $84.2 \pm 1.8 \mathrm{cmH}_{2} \mathrm{O}$ at $6 \mathrm{~Hz}$ and $85.8 \pm 1.1 \mathrm{cmH}_{2} \mathrm{O}$ at $8 \mathrm{~Hz}(\mathbf{b})$. Dotted curves are second-order approximations. In $\mathbf{a}(\mathrm{IT}=50 \%)$, the coefficient of correlations $(R)$ and $P$ values are as follows: $6 \mathrm{~Hz}: R=0.980(P<0.001)$ and $8 \mathrm{~Hz}: R=0.987(P<0.001)$. In b $(I T=33 \%)$, $R$ and $P$ values are as follows: $6 \mathrm{~Hz}: R=0.975(P<0.001)$ and $8 \mathrm{~Hz}: R=0.977(P<0.001)$. In $\mathbf{a}(I T=50 \%)$, there were no significant differences between the aSVs with an Amp of 70 and $75 \mathrm{cmH}_{2} \mathrm{O}, 75 \mathrm{cmH}_{2} \mathrm{O}$ and maximum Amp at $6 \mathrm{~Hz}$, and between the aSVs with an Amp of $75 \mathrm{cmH}_{2} \mathrm{O}$ and maximum Amp at $8 \mathrm{~Hz}$. In the $\mathbf{b}(\mathrm{IT}=33 \%)$, there were no significant differences between all aSVs with an Amp $\geq 70 \mathrm{cmH}_{2} \mathrm{O}$ at $6 \mathrm{~Hz}$, and between all aSVs with an Amp $\geq 75$ $\mathrm{cmH}_{2} \mathrm{O}$ and between the aSVs with an Amp of 70 and $75 \mathrm{cmH}_{2} \mathrm{O}$ at $8 \mathrm{~Hz}$
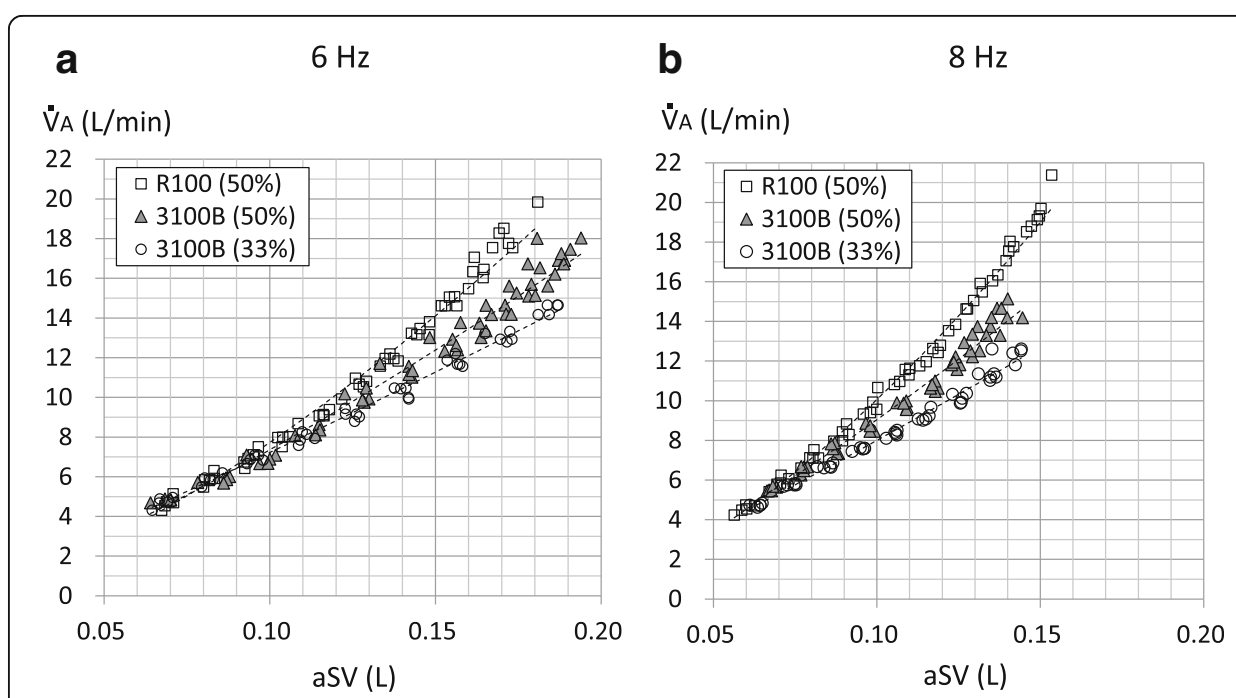

Fig. 4 Relationship between actual stroke volume (aSV) and alveolar ventilation (V). Markers indicate individual data of aSV $(\mathrm{L})$ and $\dot{\mathrm{V}} \mathrm{A}(\mathrm{L} / \mathrm{min})$. a The results at $6 \mathrm{~Hz}$. $\mathbf{b}$ The results at $8 \mathrm{~Hz}$. Dotted curves are exponential approximations. In $\mathbf{a}(6 \mathrm{~Hz})$, the exponentials (coefficient of correlations $(R), P$ values) are as follows: R100 (IT=50\%), $1.499(R=0.988$, $P<0.001)$; $3100 \mathrm{~B}(I=50 \%), 1.301(R=0.988, P<0.001)$; and 3100B $(I T=33 \%), 1.125(R=0.991, P<0.001)$. In the b $(8 \mathrm{~Hz})$, the exponentials $(R, P$ values $)$ are as follows: $R 100(I T=50 \%), 1.571(R=0.991, P<0.001) ; 3100 \mathrm{~B}(\mathrm{IT}=50 \%)$, $1.309(R=0.986, P<0.001)$; and 3100B (IT =33\%), $1.140(R=0.991, P<0.001)$ 
tions at both frequencies. It appeared that $\dot{\mathrm{V}} \mathrm{A}$ was different in three conditions with the aSV generally greater than $140 \mathrm{~mL}(0.14 \mathrm{~L})$ at $6 \mathrm{~Hz}$ and with the aSV generally greater than $100 \mathrm{~mL}(0.1 \mathrm{~L})$ at $8 \mathrm{~Hz}$ (statistical analyses were not conducted). The values of $a$ and $b$ were $0<\mathrm{a}<1$ and $1<\mathrm{b}<2$ and were different in three conditions at both frequencies (Table 1). They were highest with R100 (IT = 50\%) and lowest with 3100B (IT $=33 \%)$ at both frequencies.

Figure 5 shows the relationships between aSV (L) and VंA/aV் at $6 \mathrm{~Hz}$ (Fig. $5 \mathrm{a}$ ) and $8 \mathrm{~Hz}$ (Fig. 5b). The indicated individual datasets in the 3100B oscillator are those with an Amp up to $70 \mathrm{cmH}_{2} \mathrm{O}$ at $6 \mathrm{~Hz}$ with the IT of $33 \%$ and those with an Amp up to $75 \mathrm{cmH}_{2} \mathrm{O}$ with other settings. $\dot{\mathrm{V}} \mathrm{A} / \mathrm{a} \dot{\mathrm{V}} \mathrm{E}$ was correlated exponentially to aSV in three conditions at both frequencies (Fig. 5). It also appeared that $\dot{\mathrm{V} A} / \mathrm{a} \dot{\mathrm{V} E}$ was highest in the R100 and lowest in the $3100 \mathrm{~B}(\mathrm{IT}=33 \%)$ with the aSV generally greater than $140 \mathrm{~mL}(0.14 \mathrm{~L})$ at $6 \mathrm{~Hz}$ and with the aSV generally greater than $100 \mathrm{~mL}(0.1 \mathrm{~L})$ at $8 \mathrm{~Hz}$ (statistical analyses were not conducted).

Additional experiment: The measured aSVs with all targeted aSVs at both frequencies were not significantly different (Additional file 1$). \dot{\mathrm{V} A}$ and $\dot{\mathrm{VA}} / \dot{\mathrm{V} E}$ in the R100 (IT $=50 \%$ ) were significantly higher than those in the $3100 \mathrm{~B}(\mathrm{IT}=50 \%)$ with the targeted aSV of 160 $\mathrm{mL}$ at $6 \mathrm{~Hz}$ and with the targeted aSV of 100 and $120 \mathrm{~mL}$ at $8 \mathrm{~Hz}$ (Additional files 2 and 3). In the $3100 \mathrm{~B}, \dot{\mathrm{V} A}$ and $\dot{\mathrm{VA}} / \dot{\mathrm{V}} \mathrm{E}$ were significantly higher with the IT of $50 \%$ than those with the IT of 33\% for the targeted aSV of 120 and $160 \mathrm{~mL}$ at $6 \mathrm{~Hz}$ and for all targeted aSVs at 8 $\mathrm{Hz}$ (Additional files 2 and 3).

\section{Discussion}

This study was performed with a constant MAP and a constant BF rate and showed that the oscillator and IT\% influenced on the ventilation efficiency. We examined three conditions, i.e., R100 (IT = 50\%), 3100B (IT = 50\%), and 3100B ( IT = 33\%), with a frequency of 6 and $8 \mathrm{~Hz}$ in reference to the OSCILLATE and OSCAR trials $[1,2]$. Several studies have measured aSV during adult HFOV [8-10, 14], though nobody has investigated ventilation efficiency using adult oscillators. Lower ventilation efficiency would increase the required aSV to obtain the same alveolar ventilation for a given frequency. Therefore, ventilation efficiency might be related to the benefit of HFOV.

The basic experimental setup in the current study was the same as the last report [11]. Therefore, we omitted the detailed discussion about the methods. Also, some limitations

Table 1 The results of the values for $a$ and $b$ according to the formula that $\dot{V} A(L / m i n)=$ frequency $(\text { cycle/min })^{a} \times \operatorname{aSV}(L)^{b}$

\begin{tabular}{|c|c|c|c|c|c|}
\hline & \multirow{2}{*}{$\begin{array}{l}\text { Oscillator } \\
\text { (IT\%) }\end{array}$} & \multicolumn{2}{|c|}{$V A=k 1 \times a S V^{b}$} & \multicolumn{2}{|l|}{$k 1=$ frequency $^{a}$} \\
\hline & & $k 1$ & $b$ & Frequency (cycle/min) & $a$ \\
\hline \multirow[t]{3}{*}{$\overline{6 \mathrm{~Hz}}$} & R100 (50\%) & 242.50 & 1.4988 & 360 & 0.9329 \\
\hline & $3100 \mathrm{~B}(50 \%)$ & 146.09 & 1.3009 & & 0.8468 \\
\hline & $3100 B(33 \%)$ & 95.43 & 1.1251 & & 0.7744 \\
\hline \multirow[t]{3}{*}{$8 \mathrm{~Hz}$} & R100 (50\%) & 374.26 & 1.5705 & 480 & 0.9597 \\
\hline & $3100 \mathrm{~B}(50 \%)$ & 184.08 & 1.3089 & & 0.8448 \\
\hline & $3100 \mathrm{~B}(33 \%)$ & 110.41 & 1.1397 & & 0.7620 \\
\hline
\end{tabular}

The formula $\dot{V} A=k \times a S V^{b}$ ( $k$ is constant) is an exponential approximation formula in Fig. 4. For more information, see the text 


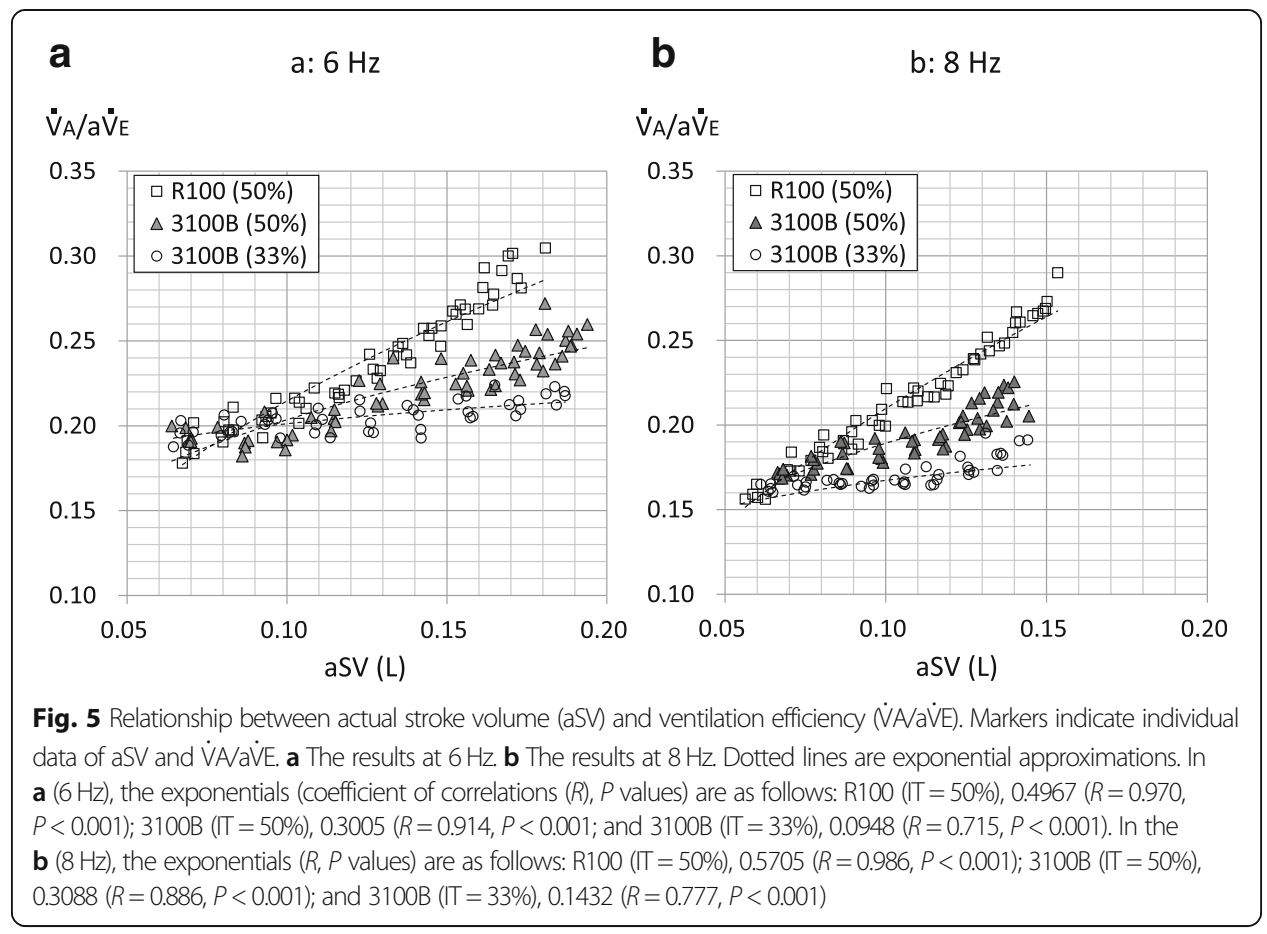

were discussed in that report [11]. One major limitation is that the absolute values of $\dot{\mathrm{VA}}$ and $\dot{V} A / a \dot{V} E$ cannot be applied to clinical situations mainly because of the incomplete bronchial tree model and rather small VD for an adult. Additionally, the lung model is far from a real lung, for example, it is rigid (not compliant) and it has only one big "alveolus." We used the R100 (IT $=50 \%)$ at a single frequency $(8 \mathrm{~Hz})$ in the last report [11], though we used two oscillators, two IT\%, and two frequencies in the current study. Our experimental setup is thought to be suitable in comparing the different events occurring outside the lung model (i.e., in the oscillator circuit) when the events occurring in the lung model are thought to be identical with same aSV, same IT\%, and same frequency. Therefore, it is thought that the effect of the oscillator with the same IT\% and same frequency is applied to clinical situations. On the other hand, the events occurring in the lung model could differ by different frequency and different IT\% even with the same aSV in the current study because of the different inspiratory and expiratory flow rate. It was reported that the gas mixing in the airway was mainly influenced by the central airway [15]. Therefore, our experimental setup likely reproduced the different events in the real lung caused by different frequency or by different IT\% to some extent, though not completely. Accordingly, our experiment provides a relative indication of the effect of the oscillator and IT\% on ventilation efficiency, but the absolute values we obtained should not be considered to be equal to what would be encountered in clinical practice.

In this study, the relationships between aSV and $\dot{\mathrm{VA}}$ (Fig. 4) or $\dot{\mathrm{VA}} / \mathrm{a} \dot{\mathrm{V}} \mathrm{E}$ (Fig. 5) are the most important. In clinical or experimental settings, the $\dot{V} A$ during HFOV had been determined as frequency ${ }^{a} \times \mathrm{SV}^{b}$ (the values for $a$ and $b$ were approximately 1 and 2, respectively) [13]. Therefore, we applied the power approximation curves to the relationships between aSV (the unit is L) and $\dot{V A}$, and those were well fitted at both frequencies (Fig. 4), similar to the last re- 
port [11]. Furthermore, we calculated the exponential for the frequency (i.e., $a)$ using cycle per minute as the unit of frequency, namely $360 \mathrm{cycle} / \mathrm{min}$ for $6 \mathrm{~Hz}$ and $480 \mathrm{cycle} / \mathrm{min}$ for 8 $\mathrm{Hz}$ (Table 1). The value for $a$ was less than 1 , and the value for $b$ was between 1 and 2 . Both values for $a$ and $b$ were highest in the R100 (IT $=50 \%)$ and lowest in the 3100B (IT $=33 \%)$ at both frequencies. This might reflect the different ventilation characteristics in the three conditions. According to the formula that $\dot{\mathrm{V}} \mathrm{A}=$ frequency $^{a} \times \mathrm{aSV}^{b}$, the formula for ventilation efficiency would be as follows: $\dot{\mathrm{V}} \mathrm{A} / \mathrm{a} \dot{\mathrm{V}} \mathrm{E}=1 /$ frequency $^{(1-a)} \times \mathrm{aSV}^{(b-1)}$. Therefore, we applied power approximation curves to the relationships between aSV (the unit is L) and $\dot{\mathrm{VA}} / \mathrm{a} \dot{\mathrm{V}} \mathrm{E}$. These were well fitted at both frequencies (Fig. 5), though we applied linear regression in the last report [11]. On the other hand, the formula of "frequency $\times \mathrm{SV}^{2}$ " (i.e., $a=1, b=2$ ) is well known as $\mathrm{CO}_{2}$ diffusion coefficient $\left(\mathrm{DCO}_{2}\right)$ which is often used as an index of $\mathrm{CO}_{2}$ removal during neonatal HFOV [16]. However, our results showed that VA during adult HFOV would not follow $\mathrm{DCO}_{2}$.

In the next three paragraphs, we will discuss the possible mechanisms for the different ventilation characteristics in the three conditions in the following order: (1) effect of the IT\% (50\% vs 33\% in 3100B), (2) effect of the oscillator with IT $=50 \%$ (R100 vs 3100B), and (3) effect of the frequency $(6 \mathrm{~Hz}$ vs $8 \mathrm{~Hz})$.

First, we will discuss the mechanisms of different ventilation characteristics due to different IT\% for a given frequency in the 3100B oscillator. With the same aSV, changing IT from $50 \%$ to $33 \%$ increases the mean inspiratory flow rate by a factor of 1.5 and decreases the mean expiratory flow rate by a factor of 0.75 . This could affect some specific ventilation mechanisms of HFOV in the lung. On the other hand, the gas regurgitation from the expiratory circuit to the inspiratory circuit during the expiratory phase of the oscillation could increase due to a longer expiratory time with lower IT\%, and this might impair $\mathrm{CO}_{2}$ washout from the oscillator circuit. Yamada et al. investigated the effect of inspiratory and expiratory time (I:E) ratio on alveolar ventilation in dogs and reported no difference between the I:E ratio of 1:1 and 1:4 [17]. In their study, BF was completely aspirated through a thin catheter placed in the ETT. Gas regurgitation during the expiratory phase of the oscillation would not occur in such systems. Consequently, their study might indicate that the observed effect in our study would mainly arise from the differences of the oscillator circuit.

Second, we will discuss the mechanisms of different ventilation characteristics due to the different oscillator with the same frequency and same IT\%. It is conceivable that the phenomena occurring in the lung model were mostly identical in this case. Therefore, the differences of $\dot{\mathrm{V} A}$ and $\dot{\mathrm{VA}} / \mathrm{a} \dot{\mathrm{V} E}$ due to the oscillator with an IT of $50 \%$ would mainly arise from the different phenomena occurring in the oscillator circuit. Since the BF rate was constant in the current study, the differences in the oscillator circuit are thought to be the main cause. The circuit of the 3100B oscillator is narrow and short compared to that of the R100 oscillator. Furthermore, the R100 oscillator has a one-way valve at the end of the expiratory circuit to prevent gas regurgitation through the expiratory valve due to the negative airway pressure during the expiratory phase of the oscillation, though the 3100B does not have this valve. Such differences would change the detailed gas movement in the oscillator circuit, and $\mathrm{CO}_{2}$ washout from the oscillator circuit might change.

Finally, it was not the aim of this study to investigate the effect of the frequency on ventilation efficiency, though we think that several factors might be involved in this 
issue. With the same aSV and same IT\%, changing frequency from $6 \mathrm{~Hz}$ to $8 \mathrm{~Hz}$ increases mean inspiratory and expiratory gas flow rates by a factor of 1.33 . Therefore, some specific ventilation mechanisms of HFOV would be strengthened in the lung. On the other hand, the need for a higher BF rate would increase with higher frequency [11]. Therefore, the effect of the frequency on ventilation efficiency in our study would be influenced by the incomplete lung model and by the relatively insufficient BF rate with higher frequency. In the large animal study which showed the superiority of higher frequency for lung protection, the aSV became lower as frequency increased [8]. The fact that the frequency used in the OSCAR trial [2] was higher than that in the OSCILLATE trial [1] would be noteworthy, and its cause might be related to the different ventilation characteristics shown in the current study.

\title{
Conclusions
}

In this lung model study, ventilation characteristics were different depending on the oscillator and IT\%. Ventilation efficiency was highest with R100 (IT =50\%) and lowest with 3100B (IT = 33\%) for high aSV ranges.

\section{Additional files}

Additional file 1: Actual stroke volume (aSV) with targeted aSV. Bar graph indicates mean aSV $(n=5)$, and vertical bar indicates standard deviation. There are no significant differences between R100 (IT =50\%), 3100B (IT = 50\%), and 3100 B (IT =33\%) with all targeted aSV at both frequencies. (PPTX $710 \mathrm{~kb}$ )

Additional file 2: Alveolar ventilation ( $\mathrm{V} A)$ measured with targeted actual stroke volume (aSV). Bar graph indicates mean $\dot{V} A$ $(n=5)$, and vertical bar indicates standard deviation. The results of the statistical significance test in Additional file $2 \mathrm{a}(6 \mathrm{~Hz})$ are as follows: R100 (IT=50\%) vs 3100B (IT=50\%): ns with aSV = 80 and 120, $P<0.001$ with aSV = 160; R100 (IT = 50\%) vs 3100B (IT =33\%): $P<0.001$ with all aSV; 3100B (IT =50\%) vs 3100 B (IT=33\%): $P<0.05$ with aSV $=80, P<0.001$ with aSV $=120, P$ $<0.01$ with $\mathrm{aSV}=160$. The results of the statistical significance test in Additional file $2 \mathrm{~b}(8 \mathrm{~Hz})$ are as follows: R100 (IT $=50 \%)$ vs 3100B ( $(T=50 \%)$ : $n s$ with aSV = 80, $P<0.001$ with aSV = 100 and 120; R100 (IT=50\%) vs 3100B ( $(T=33 \%): P<0.001$ with all aSV; $3100 B(I T=50 \%)$ vs 3100B ( $T=33 \%)$ : $P<0.001$ with all aSV. (PPTX $716 \mathrm{~kb})$

Additional file 3: Ventilation efficiency $(\dot{V} A / a \dot{V} E)$ measured with targeted actual stroke volume (aSV). Bar graph indicates mean $\dot{V} A \mathrm{~V} \dot{V} E(n=5)$, and vertical bar indicates standard deviation. The results of the statistical significance test in Additional file 3a $(6 \mathrm{~Hz})$ are as follows: R100 (IT =50\%) vs 3100B (IT =50\%): ns with aSV = 80 and 120, $P<0.001$ with aSV = 160; R100 (IT = 50\%) vs 3100B (IT = 33\%): $P<0.001$ with all aSV; $3100 B(I T=50 \%)$ vs $3100 B(I T=33 \%): P<0.01$ with $\mathrm{aSV}=80, P<0.001$ with $\mathrm{aSV}=120, P<0.05$ with $\mathrm{aSV}=160$. The results of the statistical significance test in Additional file 3b $(8 \mathrm{~Hz})$ are as follows: R100 (IT =50\%) vs 3100B (IT=50\%): ns with aSV $=80, P<0.001$ with aSV $=100$ and 120; R100 (IT = 50\%) vs 3100B (IT = 33\%): $P<0.001$ with all $\mathrm{aSV} ; 3100 \mathrm{~B}(\mathrm{IT}=50 \%)$ vs 3100B $(\mathrm{IT}=33 \%): P<0.001$ with all aSV. (PPTX $717 \mathrm{~kb})$

\begin{abstract}
Abbreviations
$\dot{V} A$ : Alveolar ventilation; $\dot{V} A / a \dot{V} E$ : Ratio of alveolar ventilation to actual minute ventilation; aV்: Actual minute ventilation; Amp: Airway pressure amplitude; ARDS: Acute respiratory distress syndrome; aSV: Actual stroke volume; BF: Bias flow; $\dot{V} \mathrm{CO}_{2}$ : Minute volume of insufflated $\mathrm{CO}_{2} ; \mathrm{CO}_{2}$ : Carbon dioxide; $\mathrm{DCO}_{2}$ : $\mathrm{CO}_{2}$ diffusion coefficient; ETT: Endotracheal tube; HFOV: High-frequency oscillatory ventilation; I:E: Inspiratory and expiratory time ratio; IT: Inspiratory time; MAP: Mean airway pressure; $\mathrm{PCO}_{2}$ : Partial pressure of $\mathrm{CO}_{2}$; SSV: Setting stroke volume; SV: Stroke volume; VD: Dead space volume
\end{abstract}

Acknowledgements

The authors thank the Metran Co. Ltd., for the use of the prototype SV measurement system.

Funding

None.

Availability of data and materials

The datasets used and/or analyzed during the current study are available from the corresponding author on reasonable request. 
Ethics approval

Not applicable.

\section{Consent for publication}

Not applicable.

\section{Competing interests}

The authors declare that they have no competing interests.

\section{Publisher's Note}

Springer Nature remains neutral with regard to jurisdictional claims in published maps and institutional affiliations.

\section{Author details}

${ }^{1}$ Advanced Emergency and Critical Care Medical Center, Okayama University Hospital, 2-5-1, Shikata-cho, Kita-ku, Okayama 700-8558, Japan. ${ }^{2}$ Center for Innovative and Translational Medicine, Kochi University Medical School, 185-1, Kohasu, Oko-cho, Nankoku, Kochi 783-8505, Japan. ${ }^{3}$ Department of Disaster and Emergency Medicine, Kochi University Medical School, 185-1, Kohasu, Oko-cho, Nankoku, Kochi 783-8505, Japan. ${ }^{4}$ Department of Critical Care and Anesthesia, National Center for Child Health and Development, 2-10-1, Okura, Setagaya-ku, Tokyo 157-8535, Japan.

\section{Received: 13 May 2018 Accepted: 28 February 2019}

Published online: 12 March 2019

\section{References}

1. Ferguson ND, Cook DJ, Guyatt GH, Mehta S, Hand L, Austin P, Zhou Q, Matte A, Walter SD, Lamontagne F, Granton JT, Arabi YM, Arroliga AC, Stewart TE, Slutsky AS, Meade MO, OSCILLATE Trial Investigators; Canadian Critical Care Trials Group (2013) High-frequency oscillation in early acute respiratory distress syndrome. New Engl J Med 368(9):795-805

2. Young D, Lamb SE, Shah S, Mackenzie I, Tunnicliffe W, Lall R, Rowan K, Cuthbertson BH, OSCAR Study Group (2013) High-frequency oscillation for acute respiratory distress syndrome. New Engl J Med 368(9):806-813

3. Hirayama T, Nagano O, Shiba N, Yumoto T, Sato K, Terado M, Ugawa T, Ichiba S, Ujike Y (2014) Mean lung pressure during adult high-frequency oscillatory ventilation: an experimental study using a lung model. Acta Med Okayama 68(6):323-329

4. Ursulet L, Roussiaux A, Belcour D, Ferdynus C, Gauzere BA, Vandroux D, Javot J (2015) Right over left ventricular enddiastolic area relevance to predict hemodynamic intolerance of high-frequency oscillatory ventilation in patients with severe ARDS. Ann Intensive Care 5(1):25

5. Dreyfuss D, Ricard JD, Gaudry S (2015) Did studies on HFOV fail to improve ARDS survival because they did not decrease VILI? On the potential validity of a physiological concept enounced several decades ago. Intensive Care Med 41(12):2076-2086

6. Guervilly C, Forel JM, Hraiech S, Roch A, Talmor D, Papazian L (2016) Effect of high-frequency oscillatory ventilation on esophageal and transpulmonary pressures in moderate-to-severe acute respiratory distress syndrome. Ann Intensive Care 6(1):84

7. Meyer J, Cox PN, McKerlie C, Bienzle D (2006) Protective strategies of high-frequency oscillatory ventilation in a rabbit model. Pediatr Res 60(4):401-406

8. Liu S, Yi Y, Wang M, Chen Q, Huang Y, Liu L, Xie J, Zhou D, Qiu H (2013) Higher frequency ventilation attenuates lung injury during high-frequency oscillatory ventilation in sheep models of acute respiratory distress syndrome. Anesthesiology 119(2):398-411

9. Sedeek KA, Takeuchi M, Suchodolski K, Kacmarek RM (2003) Determinants of tidal volume during high-frequency oscillation. Crit Care Med 31(1):227-231

10. Hager DN, Fessler HE, Kaczka DW, Shanholtz CB, Fuld MK, Simon BA, Brower RG (2007) Tidal volume delivery during high-oscillatory ventilation in adults with acute respiratory distress syndrome. Crit Care Med 35(6):1522-1529

11. Nagano O, Yumoto T, Nishimatsu A, Kanazawa S, Fujita T, Asaba S, Yamanouchi H (2018) Bias flow rate and ventilation efficiency during adult high-frequency oscillatory ventilation: a lung model study. Intensive Care Med Exp 6(1):11

12. Murray JF, Matthay MA, Luce JM, Flick MR (1988) An expanded definition of the adult respiratory distress syndrome. Am Rev Respir Dis 138(3):720-723

13. Pillow JJ (2005) High-frequency oscillatory ventilation: mechanisms of gas exchange and lung mechanics. Crit Care Med 33(3):135-141

14. Iguchi N, Hirao O, Uchiyama A, Mashimo T, Nishimura M, Fujino Y (2010) Evaluation of performance of two highfrequency oscillatory ventilators using a model lung with a position sensor. J Anesth 24(6):888-892

15. Solway J, Gavriely N, Kamm RD, Drazen JM, Ingram RH Jr, Khoo MC, Brown R, Slutsky AS (1984) Intra-airway gas mixing during high-frequency ventilation. J Appl Physiol 56(2):343-354

16. Belteki G, Lin B, Morley CJ (2017) Weight-correction of carbon dioxide coefficient $\left(\mathrm{DCO}_{2}\right)$ reduces its inter-individual variability and improves its correlation with blood carbon dioxide levels in neonates receiving high-frequency oscillatory ventilation. Pediatr Pulmonol 52(10):1316-1322

17. Yamada Y, Hales CA, Venegas JG (1986) Inspiratory-to-expiratory time ratio and alveolar ventilation during highfrequency ventilation in dogs. J Appl Phys 61(5):1903-1907 